\title{
AC 2011-633: THE IMPACT OF STEM GRADUATE STUDENTS IN THE PROFESSIONAL DEVELOPMENT OF MIDDLE SCHOOL TEACHERS IMPLEMENTING A PROBLEM-BASED INQUIRY LEARNING CURRICU- LUM
}

\section{Cher C. Hendricks, Georgia Institute of Technology}

Cher Hendricks is an educational researcher in the Center for Education Integrating Science, Math, and Computing (CEISMC) at the Georgia Institute of Technology. Prior to her appointment at CEISMC, she taught graduate courses in educational research at The Citadel and the University of West Georgia. The second edition of her book, Improving Schools through Action Research: A Comprehensive Guide for Educators, was published by Pearson in 2010.

\section{Barbara Burks Fasse, Georgia Institute of Technology}

Barbara Burks Fasse is a Senior Research Scientist in the Coulter Department of Biomedical Engineering at Georgia Tech. Dr. Fasse studies the efficacy and value of student-centered learning initiatives, specifically Problem-Based and Project-Based Inquiry Learning, in classrooms, instructional labs, and undergraduate research experiences. She joined the BME faculty in 2007 following ten years with Georgia Tech's College of Computing where she was a member of the NSF-funded Learning By Design ProblemBased Learning curriculum development and research team. Dr. Fasse also conducted an NSF-funded ethnographic study of learning in a problem-driven, project-based bio-robotics research lab at Georgia Tech. She is on the evaluation and assessment team for the SLIDER research project.

\section{Donna C. Llewellyn, Georgia Institute of Technology}

Dr. Llewellyn is the Director of the Center for the Enhancement of Teaching and Learning (CETL) at Georgia Tech. Her primary professional interests are in the area of faculty and graduate student professional development, engineering education research, and increasing access and support for underrepresented minorities in the field of engineering. 


\section{The Impact of STEM Graduate Students in the Professional Development of Middle School Teachers Implementing a Problem-Based Inquiry Learning Curriculum}

Science Learning Integrating Design, Engineering, and Robotics (SLIDER) is a five year NSFfunded research project that involves collaboration between K-12 educators, university faculty, and educational outreach specialists. The project's objective is to design and implement a problem-based learning curriculum using engineering design and LEGO robotics as the context for teaching eighth grade physical science content and process skills. One of the components of the project is to utilize science, technology, engineering, and mathematics (STEM) graduate students (Fellows) to support curriculum goals and facilitate student learning while providing the Fellows with K-12 classroom experience. A long-range goal of our project is to study the impact of the Fellows on the professional development of teachers in terms of (a) implementation of instructional strategies, (b) increasing teaching efficacy, (c) development of content knowledge, and (d) delivery of the SLIDER curriculum with fidelity.

\section{Purpose}

In this first report of the study, we begin to investigate the impact of the Fellows on seven teachers in six classrooms in two middle school contexts - suburban and rural. We are particularly interested in ways the Fellows help teachers implement a problem-based learning curriculum with fidelity. In studying impact, we focused this exploratory study on determining the ways SLIDER Fellows and teachers interact, the power distribution between teachers and fellows, and their interdependence, defined as a reciprocal relationship that "exists when the outcomes of individuals are affected by their own and others' actions" (Johnson \& Johnson, 2009 , p. 366). It is our belief that ways teachers and Fellows interact, their relationships, interdependence, and power distribution ultimately affect Fellows' ability to help teachers implement the curriculum with fidelity.

This research informs our larger study to determine the effectiveness of a problem-based learning curriculum using LEGO robotics on increasing students' physical science content knowledge and process skills. One of our secondary research questions for that study focuses on the types of support and professional development needed to adequately prepare teachers to deliver the new curriculum. The SLIDER Fellows are an integral part of this professional development, spending one day each week in a classroom with the SLIDER teacher, and so it is essential to determine the Fellows' impact on curriculum implementation and teacher development. Our purpose in studying factors such as power distribution, ways teachers and Fellows interact, and interdependence is to discover ways to leverage positive aspects of the teacher-Fellow relationship and identify and improve any difficulties so Fellows will have the greatest impact possible in the classroom, both in their interactions with students and with teachers.

\section{Fellows Programs}

An aspect of SLIDER is to provide classroom support through placing collaborating graduate students in the classrooms. Thus, Georgia Tech's STEP Fellow program was used as the model. 
To set the context of this study, both STEP and SLIDER Fellow programs are described in detail in the next sections of the paper.

STEP Program Overview. Georgia Tech's Student and Teacher Enhancement Partnership (STEP) is a National Science Foundation (NSF) funded program (GK-12) designed to improve teaching-related communication and leadership skills of our graduate students while leveraging the scholarly expertise of the academic community for the purpose of increasing the mathematics and science performance of K-12 students in the region (see http://www.cetl.gatech.edustudents/ step/overview.htm). STEP Fellows partner with metro area high school teams led by master teacher-coordinators. STEP Fellows participate in summer training workshops where they learn about inquiry-based learning pedagogy, classroom management, effective teaching skills, and appropriate uses of educational technologies. Fellows also work with K-12 personnel to develop a needs assessment and action plan for the school. During the school year, Fellows work in teams (typically two of our students) with their partner school, engaging in activities such as (a) instructing students, (b) assisting with teacher professional development, (c) providing student enrichment and mentoring, (d) creating and implementing classroom websites, (e) assisting with science fair projects, and (f) giving university lab tours.

The objectives of the STEP Program are:

- to provide Fellows with the training required to enable them to effectively communicate standards-based science and mathematics to both (a) high school students from diverse backgrounds and (b) high school science and mathematics teachers;

- to pair Fellows with master teachers in metro-area high schools to enable them to experience effective teaching methods and real-life teaching challenges;

- to provide Fellows with rewarding practicum experiences during which they can practice science and mathematics pedagogy and classroom management strategies by engaging in direct inquiry-based science content instruction during in-school classes and after-school enrichment activities;

- to introduce high school teachers and students to the use of appropriate educational technologies that complement and strengthen their course curricula and provide increased opportunity for inquiry learning by students; and

- to facilitate the development of constructive mentoring relationships between the Fellows and students from participating schools and between the participating teachers and university students and faculty.

The primary benefits anticipated for STEP Fellows are an improvement in science and mathematics teaching skills, communication, and general leadership. These outcomes are, in part, the effect of STEP Fellows' experiences working with accomplished classroom teachers and helping teachers master new academic content material. STEP Fellows' communication skills, as well as their understanding of diversity issues, improve as they work with students individually and in small groups. Further, STEP Fellows gain a deeper appreciation for the complexities of the educational challenges that affect the pipeline producing our next generation of scientists, mathematicians, and engineers. Understanding these complexities is necessary in order to strengthen the partnership between the academic, scientific, and engineering community and the school systems that provide these communities with students. 
In addition to benefits to the Fellows, the participating K-12 community and Georgia Tech benefit from this program in many ways. Teachers obtain new content knowledge and an improved understanding of science, the scientific process, and the integrated nature of knowledge, and they develop valuable personal connections to scientists and engineers at Georgia Tech. High school students benefit from improved science teaching and interactions with classroom mentors who have chosen to pursue science, mathematics, or engineering as a career. Closer connections between the university and students in the surrounding school systems has the potential to result in more students, particularly those from under-represented minority groups, enrolling in STEM degree programs at Georgia Tech.

SLIDER Fellows Program. The SLIDER Fellows program follows the same model as the STEP program but is part of a separate initiative with a different NSF funding source (DR K-12). Like their STEP counterparts, SLIDER Fellows participate in summer training workshops to familiarize them with inquiry-based learning pedagogy, classroom management, and effective teaching skills. In addition, they participate with partner teachers in an intensive summer professional development program aimed at learning about the SLIDER curriculum and its implementation. During the school year, they work in pairs at one of the partner middle schools assisting the teachers with the implementation and assessment of the new curriculum. In the early stage of this project, the Fellow role was loosely defined as providing hands-on support in the classroom one day per week during implementation of activities.

To be eligible for the program, graduate students must be familiar with robotics and engineering design, have an interest in LEGO Mindstorm robots, and be from a field that uses physics concepts. SLIDER Fellows work in their partner schools approximately five hours per week and engage in an additional two hours per week of preparation time. SLIDER Fellows receive a tuition exemption, a stipend, and a travel allowance to and from their partner schools. In addition to the work they do in their partner schools, Fellows take part in bi-weekly group meetings with the STEP Fellows and program directors and participate in ongoing professional development with their partner teachers and the SLIDER curriculum and research teams. SLIDER Fellows work in schools for one academic year, and new Fellows are chosen each year.

\section{Research Questions}

To investigate SLIDER Fellows' impact on their partner teachers' use of problem-based learning, we began by examining the relationships between teachers and Fellows. Understanding factors such as relationship, interdependence, and power distribution allows us to set into context findings related to the impact Fellows have on teachers' teaching practices and implementation of the new curriculum. In this study we focused on two primary research questions:

- What is the nature of the interdependence between teachers and the SLIDER Fellows and how is power distributed in the teacher-fellow relationship?

- How does the relationship between teachers and Fellows, particularly related to interdependence and power, impact teachers' instructional practices? 


\section{Research Design}

To study the relationship between Fellows and their partner teacher(s), we relied on case study design, described by Yin (2003) as "an empirical inquiry that investigates a contemporary phenomenon within a real-life context, especially when the boundaries between the phenomenon and context are not clearly evident" (p. 13). In this study, it was necessary to consider contextual factors that influenced the teacher-Fellow relationship so we may ultimately determine how those factors may relate to implementation of the problem-based learning curriculum. Because we believed the teacher-Fellow relationship and factors related to implementation were interrelated, we were compelled to choose a design that would allow us to investigate various aspects of the teacher-Fellow relationship, such as interdependence and power distribution. Case study design allowed for this type of investigation.

Further, because each school setting, and indeed, each classroom, was a "bounded system" (Creswell, 2007) - bounded by setting, teacher, time, and Fellow—we chose a multiple case study design for this initial investigation. As Stake (2006) explains, in a multiple case study design, single cases are examined that belong to a larger group of cases. In our study, each classroom offered a single case that was part of a larger group of classrooms implementing the problem-based learning curriculum. Thus, the cases were bound together by that common feature. An advantage of the multiple case study design is its increased generalizability of results. Merriam (2009) asserts, "The more cases included in a study, and the greater the variation across the cases, the more compelling an interpretation is likely to be" (p. 49). This claim is supported by Yin (2003), who explains that there are analytic benefits to using multiple cases in case study design.

\section{Methods}

Participants. Participants in this study were Fellows and the teachers with whom they worked. Both groups are described in detail in this section. The Institutional Review Boards (IRB) of both the university and participating school systems approved this study. All participants signed IRBapproved informed consent documents. Pseudonyms are used throughout this paper to protect the identity of the participants.

SLIDER Fellows: Cohort 1, 2010-2011. A joint application was developed to allow graduate students to apply for both programs, SLIDER and STEP Fellows, or to select to focus on only one if they had a firm preference. Although some applicants chose to be considered for both programs, some experience with or knowledge of robotics, LEGOS, and/or applied physics was preferred for acceptance to SLIDER. An additional factor considered by program administrators was the suitability of the curriculum and age group (high school vs. middle school) for supporting an applicant's interests, goals, and content expertise.

Six students were chosen for the 2010-11 SLIDER Fellows program—one female, five male. Three Fellows are enrolled in Ph.D. programs: Materials Science Engineering, Electrical Engineering, and Mechanical Engineering. The three students enrolled in Master's degree programs are in Electrical and Computer Engineering and Industrial Design. With the exception of one Fellow's undergraduate degree in Applied Physics, all have completed undergraduate 
preparation in engineering majors, three from within Georgia Tech. All of the Fellows are U.S. citizens; one is African-American, one is Asian, four are Caucasian.

SLIDER Fellows were assigned, in pairs for mutual support and carpooling, to their schools based on several criteria: geographical proximity to the Fellow's home, ethnicity, goals, and the administrators' historical knowledge of the needs of the individual milieu. After receiving their assignments, the Fellows traveled to the schools in the spring to observe the science classrooms as a part of their training, although they may not have directly observed or interacted with the individual teacher with whom they would work during the 2010-11 school year.

The Fellows were assigned to teachers as a shared or individual resource at the local level through consensus among each school's administrators, teachers, and the Fellows. In some cases, Fellows were assigned to a specific teacher and classroom without variance, and in others, Fellows floated between two or three teachers, developing a relationship with all of the teachers and their students. Table 1 provides data on Fellows, their school assignments, and the teacher or teachers with whom they partnered.

Table 1. Fellow Demographics, School Placement, and Partner Teacher(s)

\begin{tabular}{cccc}
\hline Fellow & Graduate Program & $\begin{array}{c}\text { School } \\
\text { Placement }\end{array}$ & $\begin{array}{c}\text { Partner } \\
\text { Teacher(s) }\end{array}$ \\
\hline Richard & M.S. & Turner \\
& $\begin{array}{c}\text { Electrical \& Computer } \\
\text { Engineering }\end{array}$ & Rural & \\
Brian & M.S. & & Smith \\
& Electrical \& Computer & Rural & Turner \\
Engineering & & Gray \\
Laura & Ph.D. & Miller \\
& Materials Science & Rural & Reese \\
& Engineering & & Gray \\
Doug & M.S. & & Miller \\
& Industrial & Reese \\
& Design & & King \\
Garret & Ph.D. & & \\
& Electrical & Suburb & Gentry \\
& Engineering & & \\
\hline \multirow{2}{*}{ Qi } & Ph.D. & Suburb & \\
& Mechanical & & \\
\hline
\end{tabular}

Teachers. Seven teachers are participating in the project. School 1 and School 3 each have two teachers, and School 2 has three. On average, the teachers have 12 years teaching experience with a range of 6 to 25 years. Their experience in teaching $8^{\text {th }}$ grade physical science ranges from 3 to 11 years with a mean of 6.7 years. The two teachers at School 1 earned bachelor's degrees in a science content field and then completed a post-baccalaureate program to 
become certified to teach. Both also completed graduate programs in education. The two teachers at School 2 completed traditional teacher education programs in fields outside science education. One teacher also completed masters and specialist degrees in middle grades education and is nationally board certified. The other teacher is currently enrolled in a master's in education program. Two teachers at School 3 completed bachelor's degrees in a content field (one in biology and one in family and consumer sciences) and then became certified (one through a post-baccalaureate program and the other through a Masters of Arts in Teaching program). The third teacher completed a traditional teacher education program in middle grades. All three teachers have completed at least one graduate program in an education field.

Schools. Three schools are participating in SLIDER. School 1 is the largest school, serving over 1100 students. It is the most racially diverse of the three schools, and fewer than half of the students are economically disadvantaged. School 3 has just under 1000 students, a large majority of whom are African-American, and School 2 has fewer than 700 students about half of whom are white and half of whom are African-American. Both of these schools are Title I schools serving $75 \%$ economically disadvantaged students. We relied on the National Center for Educational Statistics classifications to determine school locales. School 1 is classified as a Suburb, Large school, defined as a territory outside a principal city and inside an urbanized area with population of 250,000 or more. Schools 2 and 3 are classified as Rural, Fringe, defined as a territory outside a principal city and inside an urbanized area with population of 250,000 or more.

\section{Data Collection}

This research report utilizes qualitative methods in a multiple case study design. Data sources include group and individual face-to-face and written interviews with the Fellows, teacher surveys, fieldnotes from observations, classroom artifacts, self-report documents such as surveys, and the Fellows' weekly journals. Factors of interest include teacher-Fellow interdependence, power distribution, and teacher practices. Analyses were used not only to describe ways in which Fellows are currently impacting teachers' professional development but also to plan for ways Fellows can have a greater impact on teachers' professional development in the remaining years of the study.

Interviews. At the end of their first semester in the schools, SLIDER Fellows were interviewed. The purpose of the interview was to provide Fellows an opportunity to describe their work with teachers. Questions focused on the Fellows' goals and their perceptions of teachers' goals, ways in which Fellows spent their time in the classroom, relationships between Fellows and teachers, collaboration with teachers, Fellows' perceptions of their impact on teachers and students, and implementation of the problem-based learning curriculum. The interview protocol is provided in Appendix 1.

Another source of interview data was the bi-weekly program debriefing sessions attended by both STEP and SLIDER Fellows. In these group interviews, Fellows discussed their experiences and observations and provided specific examples of their contribution in the classrooms, possible explanations for what they were seeing/experiencing in the field, and ways they could extend their value to the teacher/classroom/students. 
Fellows' Journals. All SLIDER Fellows were required to journal throughout their participation in the program. This started during the summer training program when they were asked to reflect about the effectiveness of the summer training and how prepared they felt to enter the classrooms at the start of the school year. Throughout the fall semester, the fellows were instructed to post a weekly journal entry on our online collaborative platform (T-Square, based on the sakai program) about their experiences at the school and their reflections about what successes they were having and the areas in which they hoped to improve. Fellows were also encouraged to read each others' posts and to comment on these (this includes the sister STEP program Fellows as well). During the spring semester, SLIDER Fellows will be asked to write journal entries based on specific prompts. Responses will be used to evaluate more deeply the relationship between Fellows and their partner teachers, issues related to implementation of the BPIS curriculum, and additional professional development needs of both teachers and Fellows for the purpose of implementing the SLIDER curriculum with fidelity.

SLIDER Applications. On the program application, each SLIDER participant provided an open-ended, essay-style explanation of (a) his/her a prioi goals for participation in the SLIDER program and (b) his/her specific experience with robotics and LEGO. These data allowed us to compare the Fellows' expressed predicted goals with shifts in goals once they got into the schools and their actual attainment of those goals. Additionally, the applications provided us with demographic data as well as details about their academic history and their experiences with other mentoring, volunteering, or tutoring opportunities.

Surveys. We developed a teacher survey for the purpose of triangulating research data. Survey items were aligned with the Fellows' interview protocol. Collecting teacher data that focused on the same questions as those asked of Fellows allowed us to triangulate data and look for level of agreement between teachers' and Fellows responses. Survey items are included in Appendix 2.

\section{Data Analysis}

Following the steps described by Merriam (2009) for qualitative analysis, we first used open coding when reviewing each of our data sources. Open coding allowed for initial category construction as themes emerged from the data. Our process was to review each data source and note themes descriptively. Following that, we engaged in analytic coding to categorize themes when patterns emerged. Our next step was to name each category, ensuring each was sensitizing, described by Merriam as being "as sensitive as possible to what is in the data" so that an outsider could "read the categories and gain some sense of their nature" (p. 186). We also focused on creating exhaustive categories so that all relevant data were placed into a category and ensuring categories were mutually exclusive (Merriam). Following the protocol for multiple case study design, after coding data and developing categories, we reviewed data within each case (by Fellow-teacher pair) and then across all cases.

\section{Results}

At the outset of analyzing our data, we entered into the process assuming the case in our multiple case study design was the classroom, of which there were seven with six Fellows. However, as we immersed ourselves deeper into the data, we began to see the ways Fellows interacted 
differently with the same teacher in those instances where teachers worked with more than one Fellow. Thus, we considered the Fellow to be the unit of analysis in our case. However, as we examined relationships between a Fellow and a teacher and the factors influencing that relationship, we noted that the role one Fellow took with one teacher might not be the same role taken with another.

Roles. Fellow roles emerged as we coded and categorized the data. First to emerge were the identifying characteristics of the work Fellows were doing in various classrooms. As we noted differences among these kinds of work, we also determined that each role could be described as revealing either active or passive engagement by the Fellow. Thus, our understanding of roles revealed two levels, the first defined by the type of work Fellows engaged in (as Observer, Mentor, Tutor, or Partnering Teacher) and the second level, which was role-dependent, defined by whether the engagement was active or passive. We identified the Observer role as passive and the other three roles as active. Roles are described and illustrated below.

Observer. When Fellows are in an Observer role, there is an absence of both physical and verbal engagement with the students and/or the teacher. Fellows may watch what is occurring in the classroom and may even be engaged in their observations, making notes about the lesson or observing students completing assignments. However, as passive Observers, Fellows do not interact with students, nor do they actively participate in lesson delivery.

To illustrate, Laura described her work in a particular class with a teacher who often gave students book work to complete during class time. During those times, she took on the role of the student and became a passive learner in the class, just as she observed the students becoming passive learners. As she explained, "If they're doing directed reading...they just sit there and one person reads, and another person reads, and another person reads, and then they do a worksheet on the reading....boring!"

Each Fellow expressed a time when he or she took the role of Observer, though this generally occurred early in the semester after Fellows first started their work in the schools. In Richard's journal, for example, he noted he did not move out of the Observer role until his fourth visit to the school, when the teacher asked him to help her with a demonstration. Over the course of the semester, Fellows took on more active roles, slipping back into the Observer role during times when teachers lectured, gave students book work to complete, or - in one case-modeled lesson delivery for her Fellow and later in the day allowed him to lead the lesson.

Mentor. Fellows in a Mentor role are actively engaged with students and serve as a role model for them. In the Mentor role, Fellows serve several purposes, including (1) demonstrating that academic achievement is not bounded by geography or gender, (2) offering career modeling by explaining or demonstrating what it is that engineers do, and/or (3) engaging with students who may get little personal attention during a typical class period.

We saw several examples of the ways in which Fellows enacted the role of Mentor to provide students the opportunity to see the possibilities of the students themselves one day becoming college students, engineers, or scientists. For example, at our most rural school, one Fellow whose socio-historical and rural geographical background was similar to the students he worked 
with encouraged students to consider attending college as he had. Both Fellows at that school discussed their experiences as engineers with curious students, using that curiosity as an opportunity to explain what engineers do and ways engineers use math and science to solve problems. Both Fellows' partner teachers also expressed the positive mentoring role the Fellows had taken. As one teacher explained "...they initiate conversations with the students and are always encouraging them to pursue their education. The guys in the class especially relate to the [male] Fellows." The other teacher confirmed this in his survey, stating, "[The Fellows] have been very personable and good role models for our students. Our male students enjoy talking and discussing with them."

Laura's response to an interview question about the impact she has had on students revealed the ways she steps into the mentor role, particularly with girls. As she explained,

I think the girls are especially happy to see me...they can't really use [their male teacher] as a role model in terms of science, but they see me and they think, "She's really smart and she's a girl," and I have made connections with a lot of the girls from the classes-more than the boys. I've sort of made connections [with a few boys], but the girls especially see me as, like, an example of what they could be if they work hard enough... a lot of the time they'll say stuff to me like "Oh, girls can't, you know, I don't want to get my hands dirty and I don't want to work with all that dirty stuff," and I [say], "Well, I work with dirty stuff." Or [they'll say], "Girls can't be scientists," and I [say], "Wait a second, what do you think I am?"

Qi, a Fellow at School 3, also described the mentoring role he took with students, bringing in work from his area of research (assistive technology) to show them what engineers do and the impact the work can have. By demonstrating the kinds of work engineers do, Qi hoped to inspire students to work harder in science. Thus, his mentoring occurred more through demonstration of ways science is applied in life - a different way of mentoring than Laura's and the way Fellows' at School 2 mentored, which relied more on individual conversations with students.

Five of our six Fellows described work with students that we categorized as falling into the Mentor role. In addition, four of seven teachers described times when Fellows served as mentors to students. We also observed that at times Fellows easily shifted between a Mentor and Tutor role, depending on their assessment of what students most needed at the time.

Tutor. In the Tutor role, Fellows provide students with one-on-one or small group assistance when they encounter problems with content or procedures. The Tutor is an active role with a high level of academic engagement. In this role, Fellows must be able to articulate content and concepts to students on a level they can understand.

The majority of Fellows' time was spent in the Tutor role. Teachers often relied on the Fellows to work with students one-on-one or in small groups or to simply move about the class during the lesson and/or seat work and help students who seemed to be struggling. All Fellows described times when they were in the role of tutor, and teachers expressed that they most often relied on Fellows to take on the Tutor role. 
Most Fellows described their work as Tutor as a way to help students understand concepts in science and math. Both Fellows at School 1 noted difficulties students have with math skills, and each have taken steps to help students improve in this area. As Doug explained,

...the students are really, really weak in math and I want to help them get up to par in math. I've noticed that many students have a hard time manipulating equations and doing multiplication and division. I want to be sure that they get much stronger in those areas because that would give them more success in both math and science.

Fellows also described times when their partner teachers simply wanted them to be available to students who had questions, were struggling with concepts, or were off-task. Both Fellows at School 2 said that the majority of their time in the school had been in Tutoring roles, describing a typical day as one where they pass out materials for the teacher, wait until the lecture is concluded or the assignment has been given, and then walk around the room helping students as they need it. As Richard explained, "Usually we'll walk around, depending on how the lab is set up, either just checking with groups randomly or waiting until they raise their hands."

One Fellow at School 1 specifically noted an additional aspect of his role as Tutor: classroom management. In his interview, Doug stated, "I am used as an extra resource in the classroom and another classroom manager...I am also used to keep the class in order and to serve a larger number of students on a one-to-one basis." When asked how he spent the majority of his time at the school, he went on to explain, "I've really spent the majority of my time helping with classroom management, keeping children in line and helping facilitate the lesson."

In instances where teachers were lecturing or giving book work, Fellows described times where, instead of being passive Observers, they took the initiative to become more actively engaged and moved into a Tutor role. In his interview response, Garret noted his plan to become more involved as a Tutor, stating

This next semester my goal is to get more one-on-one tutoring with the students when the teacher is lecturing. I hope to pull people aside to help them on concepts they find difficult. This was difficult last semester because if I pulled people aside for part of a class, they would miss out on time on their project.

Thus, Fellows revealed their ability and desire to easily shift between roles based on their goals, their perceptions of student needs, and their understanding of teacher expectations.

Partnering Teacher. Fellows in the role of Partnering Teacher take on a great deal of responsibility for independently preparing lesson plans to deliver content or demonstrations to supplement their partner teacher's lesson plan. In this active role, Fellows conduct whole class lecture, lead class discussions, run a lab, or prepare and deliver a demonstration connected with a unit concept. They may be wholly responsible for their part of the instruction or demonstration, or they may partner with the teacher to co-deliver the lesson. 
Five of the six Fellows described instances where they became partner teachers, and in each of these cases, the Fellow took the initiative to create a lesson or demonstration that would fit into a standards-based unit plan. The Partnering Teacher role relies a great deal on the Fellow independently planning and delivering a lesson or demonstration and taking the initiative to find a place where the lesson will fit. This was the most common way Fellows enacted their role as Partnering Teacher.

Laura described two times when she did this. The first occurred as the result of a science planning meeting she attended where the topic of preparing students for the Science Fair was discussed. Laura interjected that she had a student-level presentation already completed on creating science fair projects and asked if the teachers would like to use it. Instead, the teachers asked Laura and Doug to take full responsibility for preparing and delivering the science fair lesson, which they agreed to do.

The second example of the Partner-Teacher role Laura described was two demonstration lessons she gave on mixtures/solutions and the periodic table, demos she suggested that would align with the curriculum teachers were covering. Both Fellows at School 2 also described one demonstration lesson they created, also independent of the teacher, using dry ice to illustrate concepts in phases of matter. Like Laura, the Fellows at School 2 looked ahead at the curriculum, found an area they wanted to plan a demonstration or lesson around, and then asked their partner teachers if they could create and deliver the demonstration.

The Partner-Teacher role described to this point relies a great deal on the Fellow independently planning and delivering a lesson or demonstration and taking the initiative to find a place where their lesson will fit. This was the most common way Fellows enacted their role as PartnerTeacher.

Qi, however, described a more collaborative nature to his Partner-Teacher role, explaining,

I believe a lot of my work was done through true collaboration. Before my lesson, I would ask [my partner teacher] what the students did, their prior knowledge since the week before, and what topic they are doing on the day I'm teaching. She would tell me about misconceptions (if any) or what students historically struggled with so that I can fully prepare. I would tell her my lesson plan ahead of time to see if she thinks it'll work in the amount of time I have.

This Partner-Teacher role was confirmed by the teacher Qi worked with, who was comfortable allowing Qi to serve as the lead-teacher while she and her co-teacher took on the role of Tutor. As the semester has progressed, Qi has taken on the responsibility of preparing and teaching weekly lessons on the day he is in the school.

Table 2 is included here to further illustrate Fellows' roles and their frequency of occurrence with different partner teachers. In the case of Richard and Brian, when they worked with the same teacher, they engaged in exactly the same roles, mainly as Observers and Tutors. When Brian worked with a different teacher, however, he had opportunity - though extremely limited - to slip into the role of Partnering Teacher. Experiences for Laura and Doug, though 
they both worked with each of the three teachers at their school, varied, with Laura having more opportunities for taking an active role in Mentoring and serving as Partnering Teacher than did Doug. Garret and Qi, though at the same school, worked with different teachers and had vastly different experiences in their roles, with Garret spending most of his time in the role of Tutor, and Qi spending almost all his time in the role of Partnering Teacher.

Table 2. Frequency of Fellows' Roles

\begin{tabular}{|c|c|c|c|c|c|}
\hline Fellow & $\begin{array}{l}\text { Partner } \\
\text { Teacher }\end{array}$ & Observer & Mentor & Tutor & $\begin{array}{c}\text { Partnering } \\
\text { Teacher }\end{array}$ \\
\hline Richard & Turner & Often & Occasionally & Often & Never \\
\hline Brian & $\begin{array}{l}\text { Turner } \\
\text { Smith }\end{array}$ & $\begin{array}{l}\text { Often } \\
\text { Often }\end{array}$ & $\begin{array}{l}\text { Occasionally } \\
\text { Occasionally }\end{array}$ & $\begin{array}{l}\text { Often } \\
\text { Often }\end{array}$ & $\begin{array}{l}\text { Never } \\
\text { Rarely }\end{array}$ \\
\hline Laura & $\begin{array}{l}\text { Gray } \\
\text { Miller } \\
\text { Reese }\end{array}$ & $\begin{array}{l}\text { Occasionally } \\
\text { Often } \\
\text { Occasionally }\end{array}$ & $\begin{array}{l}\text { Occasionally } \\
\text { Rarely } \\
\text { Occasionally }\end{array}$ & $\begin{array}{l}\text { Often } \\
\text { Often } \\
\text { Often }\end{array}$ & $\begin{array}{l}\text { Occasionally } \\
\text { Rarely } \\
\text { Occasionally }\end{array}$ \\
\hline Doug & $\begin{array}{l}\text { Gray } \\
\text { Miller } \\
\text { Reese }\end{array}$ & $\begin{array}{c}\text { Often } \\
\text { Often } \\
\text { Occasionally }\end{array}$ & $\begin{array}{l}\text { Never } \\
\text { Never } \\
\text { Never }\end{array}$ & $\begin{array}{l}\text { Often } \\
\text { Often } \\
\text { Often }\end{array}$ & $\begin{array}{c}\text { Occasionally } \\
\text { Never } \\
\text { Rarely }\end{array}$ \\
\hline Garret & King & Often & Occasionally & Often & Occasionally \\
\hline Qi & Gentry & Occasionally & Frequently & Often & Frequently \\
\hline
\end{tabular}

Our data analysis revealed that the roles taken by Fellows are influenced by the interaction between power distribution and goal expectations, both Fellows' and teachers'. Also, the Fellows' roles were observed to by dynamic, shifting across time, across teachers, or even within one lesson with one teacher. In the next section of the paper, we describe Fellow-teacher power distribution and set within those descriptions findings regarding interdependence and Fellow impact.

Power Distribution, Interdependence, and Fellow Impact. As indicated by our research questions, we originally believed that three factors - interdependence, power distribution, and impact - were discrete, allowing us to address them individually. However, what we discovered is that interdependence and impact are actually dependent on power distribution. In this section of the paper, we describe Fellow-teacher power distribution, and we set within those descriptions our findings regarding interdependence and Fellow impact on teachers' instructional practices.

Power Distribution. In analyzing Fellows' journal entries and interview responses, it became clear that teachers varied in terms of the amount of control they were willing to 
relinquish in their classrooms. This disposition toward control—which we categorized as high control, low control, or relinquishment of control - had a direct impact on teachers' (1) openness to allowing Fellows more responsibility for lesson planning and delivery and (2) depth of collaboration with Fellows, factors that defined power distribution and which ultimately influenced interdependence and Fellow impact.

High Control. Two of the seven teachers maintained a high disposition toward control in their classrooms, which prevented their Fellows from stepping into the role of Partnering Teacher. In each case, Fellows spent a significant amount of time as Observers, though they were able to assume the roles of Tutors and Mentors when class activities allowed for their involvement with students (e.g., during group work or lab activities). Teachers with high dispositions toward control collaborated least frequently with Fellows.

Richard's partner teacher, for example, did not relinquish any control over the course of the semester to allow him to assume significant responsibility for lesson planning or delivery. Though he and Brian did create and deliver one 15-minute demonstration, this occurred at the Fellows' suggestion and there was no collaboration between the Fellows and teachers in planning the demonstration or making sure it was clearly connected to content and standards.

Richard and Brian stated in their interview that the tight control maintained by one of their partner teachers was likely due to the pressure she felt to meet standardized testing goals and cover the state science standards. As Richard explained, "We're halfway through the year, and we're behind [in covering content]. I think that... hurts [the teacher]'s flexibility...to be able to put us in to do a lesson on something. I think she wants to cover the stuff herself-the important things." Brian confirmed that, adding, "[And that] keeps us in the role we're in." In her survey response, this teacher said Fellows spent the majority of their time "being a facilitator," a choice she said she made. There was no indication in any data source that this teacher and the Fellows decided together what role the Fellows would take in the classroom.

In the second case where the teacher kept a high level of control in the classroom, that control was related to the teacher's desire to maintain discipline, and the teacher's primary way of managing the classroom was in giving students book work to complete. Because students engaged in so much book work, there was little opportunity for Fellows to do much more than be Observers, though sometimes they moved out of that role and into the role of Tutor when students had questions, became bored, or were clearly struggling. Laura stated that any teaching she was able to do in this teacher's class involved taking his lesson plan and delivering it. As she explained,

...either I'll teach a lesson or I will answer individual questions during their workbook time, but it's not me planning a lesson; it's usually me taking his lesson plan, and if they're just silently sitting there, I'll jump in at the last 15 minutes of class and start going over stuff.

In cases where teachers maintained high control in their classrooms, their Fellows stated their uncertainty about the goals their partner teachers had for them, reporting that teachers had not articulated any goals for the Fellows' time in the classroom. Interdependence was non-existent in 
high control classrooms because teachers did not view Fellows as colleagues, collaborators, or partner teachers. Instead, they were seen as little more than an extra set of hands in the classroom to pass out materials, answer student questions, or help maintain order. This had a negative effect on Fellow's impact on their partner teachers because Fellows were afforded no real opportunity to (1) demonstrate their content knowledge or ways to leverage their science and engineering backgrounds to teach content, (2) model effective teaching practices for teachers who relied on bookwork and scripted lesson plans, or (3) model effective problem-based learning instructional strategies. Fellows were negatively impacted as well because of the limited opportunities available in high control classrooms to learn from experienced teachers who could have helped them develop teaching skills.

Low Control. Four other teachers maintained a lower disposition toward control, and over time became more comfortable with the Fellow assuming greater responsibility for helping with instruction, planning and delivering parts of lessons, and carrying out demonstrations and labs to supplement lecture. Fellows working with these teachers spent less time as Observers, often found themselves in the roles of Tutors and Mentors, and had occasional but limited opportunities to step into the role of Partnering Teacher. Collaboration occurred more frequently with these teachers, but was limited in scope.

Three of the four teachers with a lower disposition toward control were comfortable asking Fellows to assume full teaching responsibilities, but this almost exclusively occurred at the last minute, with little planning, when the teacher had something else to do. Though the Fellows did step in as lead-teacher, the role they assumed in these instances was Tutor. The Fellows had not planned the lesson, had limited or no time to prepare for instruction, and typically did little more than read a scripted lesson plan and lead students through pre-planned activities. Laura described her work with two different teachers as falling into this category, as did Brian with his partner teacher. Brian stated,

\section{[The teacher] will turn the class over, and I'll talk about a certain topic, or parts...but it's not ever that he just sits back and I teach the whole class...It's hard because we have a pretty good idea of what we're going to be doing next week when we come in, but we don't have a really exact idea, so we can't prepare.}

Though Laura did have opportunities to serve as Partnering Teacher on a few occasions, the role was limited to supplementing lessons with demonstrations or switching roles with one teacher who would allow Laura to deliver parts of the lesson while the teacher served in the Tutor role. It is unclear what goal this role reversal served, though it may have been used to allow the teacher to work one-on-one with students and/or gauge their learning.

Garret's work with his partner teacher did allow him significantly more responsibility for lesson delivery and preparing and delivering demonstrations to accompany lessons delivered by the teacher. However, his partner teacher maintained most of the responsibility for planning lessons, and Garrett spent the majority of his time in the role of Tutor. Garret clearly values this arrangement, though, seeing it more as a co-teaching arrangement with equal responsibility for helping students. As he stated in his interview, 
My goal each week is to help the teacher with a lesson so that there are two of us trying to guide the students at once. It is so easy to slip into having one of us guide while the other one helps only slightly.

Most Fellows who worked with teachers with a lower disposition toward control reported their uncertainty about the goals their partner teachers had for them, though most perceived teachers wanted them their to assist with instruction and help out where needed. As Laura stated,

They like having me around because they are able to kind of escape for a period every week and get their [other] stuff done. So I'm kind of a break for them...[but] I don't know what their goals for me are...

Though counterintuitive, interdependence was often limited in low control classrooms because the Fellow's independence allowed him or her stand in for the teacher while the teacher attended to unrelated tasks. Fellows were able to bring in their content knowledge and practical experiences when developing demonstrations, and in some cases they were able to model for students the ways scientists and engineers solve problems. When allowed to take more responsibility for lesson delivery, Fellows often chose more engaging methods of instruction than were demonstrated by their partner teachers, but because teachers often left the classroom or busied themselves with other activities while Fellows were teaching, this modeling did not have any substantive impact on teacher development or instructional practices.

Relinquishment of Control. We can see in the case of Qi a demonstration of the affordances of a teacher's relinquishment of control of her classroom to support interdependence and impact teacher development. This particular teacher easily relinquished control of her classroom, allowing Qi, her Fellow, to plan and deliver lessons weekly. The teacher was comfortable collaborating with the Fellow, clearly trusted him with instructional responsibilities, and allowed him to assume the role of lead-teacher as she and her co-teacher moved into the role of Tutor. Qi's interview responses revealed his belief that his partner teacher enjoyed "having someone to help with lesson planning and bounce ideas around." The teacher's survey responses confirmed Qi's perception. In one response, she stated, "Qi keeps me in 'check' when I feel I am not giving my all in the classroom."

In describing his work in the classroom, Qi explained his gradual move toward taking more responsibility for lesson planning and delivery and the ways he moved through various roles, sometimes within the same day. He stated that during the first problem-based learning lessons, he served as the teacher's assistant, helping to set up activities. He went on to explain,

Sometimes she would [teach for] the first few periods in the day so that I [could] just observe, and then she would let me do the last few periods...After the intro [ductory] unit, I was able to have command of the class more, more time to do my activities, and the freedom to implement my own activity that... fit the topic of the day...[This] change was due to me being more comfortable in front of the class and more confident in the materials that I introduce. It's a very nice feeling to know that what I do is fully supported. 
Thus, in the case of Qi, he felt supported in the various roles he assumed, whether it was as Observer or Partnering Teacher. Further, serving as Observer was not a function of the teacher's desire to control the classroom but was a way to model lesson delivery for Qi before he delivered the lesson himself. Another way Qi was supported was in collaboration with the teacher, who stated in her survey that they collaborated to plan lessons each week during subject-area meetings (attended by all science teachers) and supplemented that with email, text, and phone communications to further plan. No other Fellow-teacher partnership indicated this level of collaboration.

Qi believed the positive relationship he had with his teacher was based on their shared goal of helping students succeed. He further stated that the teacher wanted him to enjoy his work with students, and she wanted him to serve as a model for them to "help immerse the students to concepts or topics that [he has] experienced as an engineer." Unlike other participating teachers, Qi's partner teacher had clear goals for him that related not only to how he could positively influence students but how he could grow as a teacher.

This Fellow role demonstrates the best example of interdependence. The professional relationship between Qi and his partner teacher was reciprocal, mutually beneficial, and framed by a shared set of goals. The partner teacher's relinquishment of control, faith in Qi's ability, willingness to let Qi fail, and belief that Qi's modeling of what engineers do would be beneficial for students - coupled with Qi's desire and enthusiasm to take control of the classroom, selfconfidence in his ability to plan and deliver lessons, willingness to fail and learn from mistakes, and desire to serve as an engineering role model — created an atmosphere of mutual trust and respect that led to powerful outcomes for the Fellow, the teacher, and students. Qi benefited by having multiple opportunities to plan and deliver lessons, fine-tune instruction throughout the day as he reflected-in-action when his plans were less successful than he hoped, and learn how to clearly deliver content in a developmentally appropriate way.

This interdependent relationship provided an opportunity for Qi to improve his teaching practice, and it also allowed his partner teacher to improve hers as well. She and her co-teacher maintained their engagement with students and within the classroom when Qi took over as leadteacher, and as a result there were three learning experiences going on: those of students, teacher, and Fellow. In this case of relinquished teacher control, we see an example of how a Fellow took and was given the Partnering Teacher role, illustrating the type of interdependence necessary for Fellows to be able to positively effect the teacher's content knowledge and/or instructional practices.

\section{Implications}

Our findings indicate that interdependence between Fellows and teachers is greatest when teachers are able to relinquish control of their classrooms and allow Fellows to take over lesson planning and instructional responsibilities, thus enacting the role of Partnering Teacher. However, for the relationship to be most beneficial for both teacher and Fellow, common goals should be established, and collaboration must be authentic and carried out in such a way that it leads to attainment of the common goals. Further, establishing goals for (1) the Fellow's professional development, (2) the teacher's professional development, and (3) student learning 
may provide the best opportunity for creating an interdependent relationship that is mutually beneficial to both teacher and Fellow.

In future studies, we will examine additional factors that may mediate a (1) teacher's ability to relinquish control and a (2) Fellow's confidence in stepping into a Partnering Teacher role. Some of these factors began to emerge in our data, including teacher and Fellow self-efficacy and dispositions, as well as teacher confidence in Fellows' ability. An in-depth study of these mediating factors will help us better understand their effects on power distribution/control, enactment of various roles, and interdependence/impact. Our goal is to use results to plan professional development activities that allow teachers and Fellows to examine their confidence, self-efficacy, general dispositions, and disposition toward control so they may better understand how to establish interdependent relationships that will be most beneficial for their professional development, delivery of curriculum, and student learning.

Research on power distribution between student teachers and their mentors may be useful in our continuing investigation. Though SLIDER Fellows' roles in classrooms are different from those of a typical pre-service student teacher, Fellows do encounter some of the same issues faced by student teachers working in classrooms with in-service teachers who serve as their mentor or collaborating teacher. The role of power described in student teaching literature may have application in future analysis of Fellows in classrooms. Factors related to power include student teachers' desire to avoid confrontation (Graham, 1999), student teacher compliance with mentor goals (Barrows, 1979), student teachers' perceptions of mentors as authorities or experts (Anderson, 2007), and whether student teachers perceive their relationship with the mentor as formal or informal (Anderson). Although the expectations of and for Fellows are not as clearly defined or rehearsed as those of the student teacher, issues related to power may be similar and, thus, support additional exploration.

\section{References}

Anderson, D. (2007). The role of cooperating teachers' power in student teaching. Education, $128,307-323$.

Barrows, L. K. (1979, April). Power relationships in the student teaching triad. Paper presented at the Annual Meeting of the American Educational Research Association (AERA), San Francisco, CA. [ERIC Document Reproduction Service, ED 173 335]

Creswell, J. W. (2007). Qualitative inquiry and research design: Choosing among five traditions ( $2^{\text {nd }}$ ed.). Thousand Oaks, CA: Sage Publications.

Graham, P. (1999). Powerful influences, A case of one student teacher negotiating his perceptions of power relations. Teaching and Teacher Education, 15, 523-540.

Johnson, D. W., \& Johnson, R. T. (2009). An educational psychology success story: Social interdependence theory and cooperative learning. Educational Researcher, 38, 365-379. 
Merriam, S. B. (2009). Qualitative research: A guide to design and implementation. San Francisco: Jossey-Bass.

Stake, R. E. (2006). Multiple case study analysis. New York: Guilford Press.

Wilkerson, J., \& Lang, W. (2007). Assessing teacher dispositions: Five standards-based steps to valid measurement using the DAATS model. Thousand Oaks, CA: Corwin Press.

Yin, R. K. (2003). Case study research: Design and methods ( $3^{\text {rd }}$ ed.). Thousand Oaks, CA: Sage Publications.

\section{Acknowledgements}

This research has been supported by the National Science Foundation. The views expressed are those of the authors. 


\section{Appendix 1. SLIDER Fellows Interview Protocol}

1. Before you started in the classroom this year, what goals did you have for your work at Middle School? What did you hope to accomplish? What did you hope to learn?

2. What has facilitated or not facilitated the achievement of these goals?

3. If you have adjusted your goals now that you have experience in the classroom, describe your revised goals and why you revised them.

4. What do you think the goals are of the teacher or teachers you've been working with?

5. Describe how the teachers use you and/or work with you in the classroom.

6. In what ways has this changed over the course of the semester?

7. Would you define any of your work with the teacher as true collaboration? If so, describe ways you collaborate. If not, explain what you think are barriers to truly collaborating with the teacher.

8. How have you spent most of your time when you've been at the school? Has this been your choice or the teacher's choice?

9. In what ways, if any, has your confidence in the classroom changed this semester? Explain and/or give an example.

10. Describe the relationship you've had with the teacher(s) you've worked with this semester.

11. What effect do you think you've had on the students you've worked with this semester?

12. What effect do you think you've had on the teacher(s) you've worked with this semester? In terms of content knowledge? Classroom management? Problem-based learning curriculum?

13. What have you learned about the problem-based learning curriculum and/or Problem-based Learning this semester as you've watched it implemented in the classroom?

14. What do you perceive to be the biggest barriers to teachers successfully implementing problem-based learning and the SLIDER curriculum? How might we deal with these barriers?

15. What have you learned about the nature of schools this semester? 


\section{Appendix 2. SLIDER Teacher Survey}

1. Before the beginning of this school year, what goals did you have for your SLIDER Fellow(s)? What has facilitated or not facilitated the achievement of these goals?

2. If you have adjusted your goals for your SLIDER Fellow(s), describe those revised goals and why you revised them.

3. As a teacher, what goals did you have for your students at the beginning of the school year?

4. How is/are your SLIDER Fellows spending most of their time while in your classroom? Is this your choice or the Fellow's choice?

5. Have there been any changes over the semester in terms of the kinds of activities the Fellows are engaging in while in your classroom? If so, what caused the change?

6. Describe ways, if any, that you collaborate with your Fellow(s). What are the barriers to collaborating with your Fellow(s)?

7. In what ways, if any, has/have your SLIDER Fellows' confidence in the classroom changed this semester? Please share any examples that might illustrate this.

8. Describe the quality of the relationship you've had with your SLIDER Fellow(s) this past semester.

9. What effect do you think your SLIDER Fellow(s) have had on the students they have worked with this past semester?

10. How has/have the SLIDER Fellow(s) influenced or helped you, if at all? 